\title{
STUDYING RECOGNITION DYNAMICS OF MONOCHROME SYMBOLIC IMAGES BY A RAPID SERIAL VISUAL PRESENTATION METHOD
}

\author{
Tarasova T.D. ${ }^{1}$, Sergeev A.P. ${ }^{1,2}$, Tarasov D.A. ${ }^{1}$ \\ 1) IRIT, Ural Federal University, Yekaterinburg, Russia \\ ${ }^{2)}$ Institute of Industrial Ecology UB RAS, Yekaterinburg, Russia \\ E-mail: datarasov@ya.ru
}

The paper describes the application of an RSVP method to study the dynamics of recognition time of visual stimuli by an untrained observer. The method is implemented on the basis of a specially developed program presenting stimulus material on a computer screen according to a given algorithm.

Studies conducted in [1] showed that the rapid presentation of a series of stimuli can increase the speed of their recognition. Although it was revealed [2] that the complexity of the pattern plays a large role in its perception. In this paper, we study the influence of spatial characteristics of stimuli on the speed of their recognition, using the example of images of letters. As the stimulus material, two capital letters "E" and "Z" were used for two fonts: Times New Roman and Art Script. In total, 4 stimuli were used, each of which was presented 100 times in random order. To create stimulus material, the letters were aligned in height and then converted into a BMP raster image file, which were displayed on a computer screen. A special program is used for the experiment, which collects respondent data, presents stimuli in a random order, and writes down the respondent's reaction time to the presented symbol in the table. A total of 1,600 presentations of four incentives were conducted for four respondents. Figure 1 shows the distribution of the average letter recognition time (ordinate axis) for all respondents from its first presentation to the last (abscissa axis). Based on the obtained set of points, a regression line was constructed with confidence intervals with a probability of 0.95 . As can be seen from Figure 1, all regression lines are increasing, which can be explained by an increase in respondents' fatigue. For the letter "E" of the Art Script font (Figure 1, a) and the letter " $Z$ " of the Times New Roman font (Figure 1, e), the regression line has the smallest slope. The authors suggest that a significant difference in the incidence of these incentives from the rest, develops a stable recognition strategy for respondents. The results of the experiment showed that the differences in recognition dynamics are not significant. Obviously, that more accurate results can be obtained by increasing the number of respondents. The study showed that the use of a special program and controlled experimental conditions greatly facilitate the obtaining and processing of the result. 
ФТИ-2020

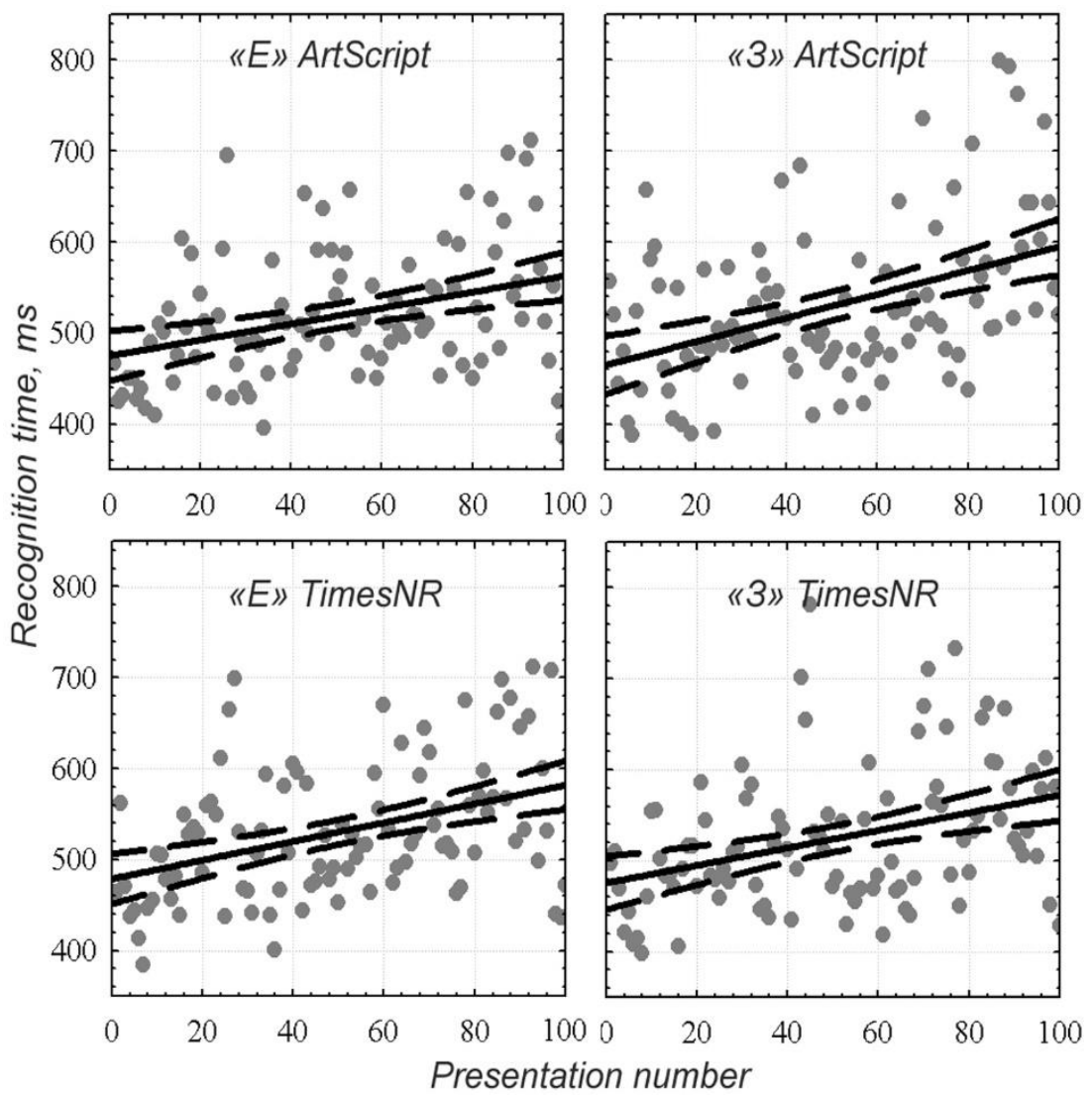

Fig. 1. Stimuli recognition dynamics.

1. Wobbrock J. O., Forlizzi J., Hudson S. E., Myers B. A. Proceedings of the 15th annual ACM symposium on User interface software and technology - UIST, 205 (2002).

2. Митрофанова В. С. Вестник Ульяновского государственного технического университета. 4, 32-34, (2015).

3. Potter M. C. Journal of Experimental Psychology: Human Learning \& Memory, 2(5) 509-522, (1976).

4. Reeves A., Sperling G. Psychological Review. 93(2), 180-206, (1986).

5. Sperling G, Weichselgartner E. Psychological Review, 102, 503-522, (1995). 